\section{Extensão universitária voltada ao atendimento de estudantes com Altas Habilidades/Superdotação}

Renata Gomes Camargo

Universidade Federal de Santa

Catarina, Brasil.

re_kmargo@hotmail.com
A 100 años de la Reforma Universitaria de 1918 /

Intervenciones

RECEPCIÓN: 24/06/17

ACEPTACIÓN FINAL: 23/10/17

\section{Resumo}

Atender as necessidades educacionais de pessoas com Altas Habilidades/ Superdotação - AH/SD — demanda ações além daquelas que podem e devem ser desenvolvidas na escola, por exemplo, programas de enriquecimento extra escolar que executam suas atividades em prol do desenvolvimento dos potenciais de estudantes com $\mathrm{AH} / \mathrm{SD}$. Este artigo tem por objetivo caracterizar o projeto Programa de Incentivo ao Talento, que configura-se como um programa de enriquecimento extraescolar e mostrar a visão dos estudantes com $\mathrm{AH} / \mathrm{SD}$ a respeito desta ação de extensão universitária. A metodologia é qualitativa, tendo por instrumento a entrevista semiestruturada e a compreensão dos dados realizada por meio da análise de conteúdo. Dentre os principais resultados tem-se a qualidade das atividades oferecidas a estes estudantes via projeto, pela riqueza de oportunidades que se tem a partir da extensão universitária.

Palavras-chave

- Altas Habilidades/Superdotação

- Extensão

- Programas de Enriquecimento Extra escolar

\section{Resumen}

Atender las necesidades educativas de personas con Altas Capacidades/ Superdotación — AC/SD — requiere de acciones además de aquellas que pueden y deben ser desarrolladas en la escuela, por ejemplo, programas de enriquecimiento extraescolar que realizan sus actividades en favor del desarrollo de los potenciales de estudiantes con AC/SD. Este artículo tiene como objetivos caracterizar el proyecto Programa de Incentivo al Talento, que se constituye como un programa de enriquecimiento extraescolar, y mostrar la visión de los estudiantes con AC/SD respecto de esta acción de extensión universitaria. La metodología es cualitativa, con instrumentos como la entrevista semiestructurada y la comprensión de los datos realizada por medio del análisis de contenido. Entre los principales resultados se cuenta con la calidad de las actividades ofrecidas a estos estudiantes por el proyecto debido a la riqueza de oportunidades que se tiene a partir de la extensión universitaria.

Palabras clave

- Altas Capacidades/Superdotación

- Extensión

- Programas de enriquecimiento extraescolar

\section{Para citación de este artículo}

Gomes Camargo, R. (2017). Extensão universitária voltada ao atendimento de estudantes com Altas Habilidades/Superdotação. Revista $+E$ versión en línea, 7(7), 338-347. Santa Fe, Argentina: Ediciones UNL. 


\section{Introdução}

Apesar dos princípios da inclusão serem indicados como orientadores da organização das escolas, estas ainda estão em processo de constituição do que seria previsto como ideal. Moreira (et al., 2011) afirmam que, desde a década de 1990, o sistema educacional tem amparo legal da proposta da inclusão escolar, porém o mesmo tem pouco poder para garantir que as práticas inclusivas sejam efetivadas. As práticas, na maioria das vezes, demonstram um distanciamento entre o que está proposto nas leis e nas produções teóricas e as ações propriamente ditas. As indicações nos documentos legais apontam que "a proposta da inclusão na educação básica precisa ter uma organização pedagógica planejada, devidamente financiada para assegurar os apoios e recursos físicos, humanos e materiais aos alunos com necessidades educacionais especiais (...) (Moreira et al., 2011:129), porém essas ainda estão em processo de implementação nas escolas.

Isso é verificado no atendimento aos estudantes com Altas Habilidades/Superdotação -AH/SD-, uma vez que, apesar das leis garantirem direitos que dão suporte para a constituição de sua acessibilidade educacional e inclusão escolar, ainda estes estudantes são pouco reconhecidos e menos ainda atendidos, como apontam as estatísticas da educação no Brasil. Tem-se o dado de que somente 5.786 estudantes com AH/SD foram declarados no censo escolar (Inep, 2009). Estes estudantes são reconhecidos na Política Nacional de Educação Especial na Perspectiva da Educação Inclusiva:

"Alunos com altas habilidades/superdotação demonstram potencial elevado em qualquer uma das seguintes áreas, isoladas ou combinadas: intelectual, acadêmica, liderança, psicomotricidade e artes, além de apresentar grande criatividade, envolvimento na aprendizagem e realização de tarefas em áreas de seu interesse". (Brasil, 2008:9)

Sendo assim, a escola precisa contar com espaços educacionais extraescolares, que deem o aporte para a identificação e reconhecimento destes sujeitos, bem como para o atendimento de suas necessidades educacionais especiais. Neste sentido, é importante destacar a amplitude da extensão universitária, tanto no âmbito das ações oferecidas para a comunidade, quanto na busca de que essas atuem na solução dos seus problemas (Carvalho, 2009).

Atender às estas necessidades de estudantes constitui-se um objetivo que tem demandado ações independentemente das leis serem colocadas em prática na escola. Este é um dos fatores, que muitas vezes caracteriza os Programas de Enriquecimento Extraescolares, dentre estes o PIT - Programa de Incentivo ao Talento, projeto de extensão abordado neste artigo, que mesmo tendo parcerias com escolas, executam suas atividades com autonomia, em prol do desenvolvimento dos potenciais de estudantes com AH/SD.

Este artigo tem por objetivo caracterizar o projeto PIT, que se configura como um programa de enriquecimento extraescolar e mostrar a visão dos estudantes com AH/SD a respeito desta ação de extensão universitária.

\section{Desenvolvimento}

Enriquecimento diz respeito à "abordagem educacional que oferece à criança experiências de aprendizagem diversas das que o currículo normalmente apresenta" (Sabatella, Cupertino, 2007:74). Gerson e Carracedo (2007) apontam a proposta de enriquecimento educacional para estudantes com AH/SD como programas instigantes e favorecedores dos potenciais desses, que contemplam experiências que geralmente a escola, por meio do seu currículo ${ }^{1}$ comum, não oferece. Os programas possibilitam que os estudantes tenham acesso à informação, conhecimentos, materiais e atividades avançadas, seguindo metodologias e estratégias que agrangem suas características e demandas socioeducativas.

Este artigo que tem seu foco sobre o projeto de extensão que caracteriza-se como um Programa de Enriquecimento extraescolar. Este programa combina aspectos do enriquecimento intracurricular, pois geralmente trazem conteúdos que são abordados na escola, aprofundando-os ou possibilitando experiências ampliadas/ diferenciadas desses, com aspectos do enriquecimento extracurricular ao oferecer aos estudantes que participam dos referidos programas atividades e vivências que, na maioria das vezes, não são ofertadas na escola (Freitas, Pérez, 2012; Sabatella, Cupertino, 2007).

Esta combinação geralmente proporciona, aos estudantes com $\mathrm{AH} / \mathrm{SD}$, que suas necessidades educacionais especiais sejam contempladas, sem deixar à margem as demandas que apresentam frente ao currículo das suas respectivas escolas. Os aspectos convergentes de muitos estudos, dizem respeito à apresentação de propostas diferenciadas pelos Programas de Enriquecimento Extraescolar. Nestes afirma-se que o
1) Define-se um currículo como um: "conjunto de propostas que levam a determinar, executar e avaliar as atividades e conteúdos oferecidos de forma sistemática aos alunos da escola" (Nicolosso, Freitas, 2002:19). 


\section{6}

é válido destacar que, exercendo o enriquecimento desta maneira flexível e sugestiva, é mais fácil de se conseguir contemplar as diversidades e peculiaridades que advêm da combinação entre $\mathrm{AH} / \mathrm{SD}$ e as diferentes áreas do conhecimento e a individualidade de cada pessoa

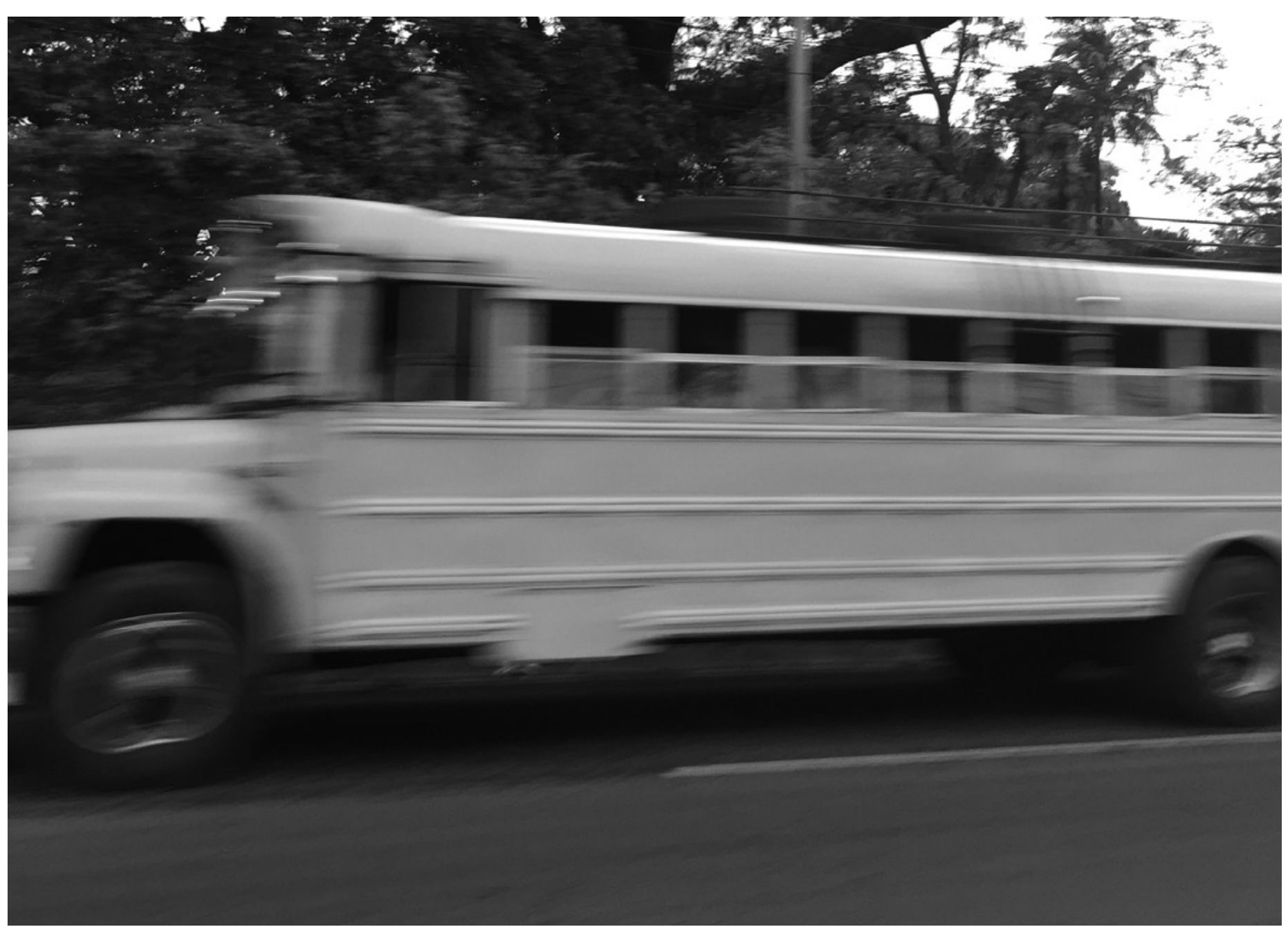

(c) Carolina Sanchis 
enriquecimento extraescolar favorece o desenvolvimento do potencial do estudante com AH/SD ao contemplá-lo em atividades da(s) sua(s) área(s) de maior interesse, contando com o apoio da comunidade extraescolar e voluntários especialistas nessas para oferecer alternativas de estudo e produção que não são oferecidas na escola (Bittelbrunn, 2003; Cruz, 2007; Fortes, 2008; Magalhães, 2006; Pinto, 2002). Este apoio mostra a magnitude que pode assumir a extensão universitária, uma vez que a participação da comunidade e voluntários é ampliada pelas parcerias que se pode buscar e são proporcionadas no âmbito destas instituições. Renzulli e Reis (2012) caracterizam o Modelo Triádico de Enriquecimento, que consiste em um programa com objetivo de estimular a produção criativa dos estudantes, por meio da oferta de oportunidades de contato com várias áreas de interesse e campos de estudo.

No desenvolver das atividades deste modelo de enriquecimento, o objetivo é instigar a aplicação e aproveitamento dos conteúdos em produções cada vez mais avançadas, aperfeiçoando as habilidades e a constituição da autonomia dos estudantes na escolha da(s) sua(s) área(s) de interesse e as atividades relacionadas a esta(s), explorando ao máximo o potencial desses (Nakano, Siqueira, 2012). O Modelo Triádico de Enriquecimento subdivide-se em atividades de três tipos, porém todas estão relacionadas, logo, não existe uma hierarquia ou ordenamento nas atividades a serem desenvolvidas na perspectiva do modelo.

Autores como Alencar e Fleith (2001), Renzulli e Reis (2012), Renzulli (2004), Sabatella (2005) caracterizam as propostas de enriquecimento como Tipo I, Tipo II e Tipo III:

1) Enriquecimento Tipo I: é planejado visando proporcionar o contato dos estudantes com atividades relacionadas a uma grande variedade de áreas do conhecimento, ocupações, diferentes profissionais, hobbies, espaços, eventos que normalmente não são oportunizados na escola. A organização destas experiências pode ser, dentre outras, por meio de minicursos, apreciação de espetáculos, exposição de conteúdos, materiais audiovisuais, viagens. Estas atividades são essencialmente exploratórias, nas quais os estudantes podem identificar sua(s) área(s) de maior interesse e na(s) qual(is) têm maiores habilidades.

2) Enriquecimento Tipo II: envolve o trabalho com materiais e metodologias que promovam o desenvolvimento do pensar/refletir e vivência de processos de trabalho. As atividades instigam o pensamento criativo e crítico sobre os conteúdos escolhidos, a resolução de problemas, a competência no uso de materiais, afetividade, aprendizagens e habilidades específicas na área de interesse selecionada pelo estudante. Isto demanda conhecimento do profissional da(s) área(s) envolvida(s) nas atividades, para que o estímulo seja o mais qualificado possível.

3) Enriquecimento Tipo III: neste os estudantes selecionam uma ou mais áreas combinadas de interesse para buscar aprofundamento nesta(s). Neste tipo de enriquecimento, os estudantes deverão estar dispostos a se assumirem como pesquisadores e assim comprometerem-se ainda mais com a sua investigação e têm autonomia para o desenvolvimento desta. Os propósitos do Tipo III a incluem objetivos como: 1) proporcionar oportunidades de os estudantes adquirirem nível avançado de compreensão dos conteúdos e metodologias na(s) área(s) eleita(s); 2) instigar o comprometimento com o seu trabalho e formulação de ideias criativas; 3) favorecer a elaboração de produtos autênticos, que possivelmente provoquem um impacto sobre público específico; 4) buscar possibilidade de expressão através de estudos interdisciplinares; 5) estimular o desenvolvimento da autonomia nas habilidades de aprendizagem, planejamento, sistematização, utilização de recursos, aproveitamento do tempo, tomada de decisões; e 6) favorecer a auto avaliação e a autoconfiança.

Veja-se, na Figura 1, o desenho esquemático proposta do Modelo Triádico de Enriquecimento:

Figura 1. Atividades previstas no Modelo Triádico de Enriquecimento ${ }^{2}$

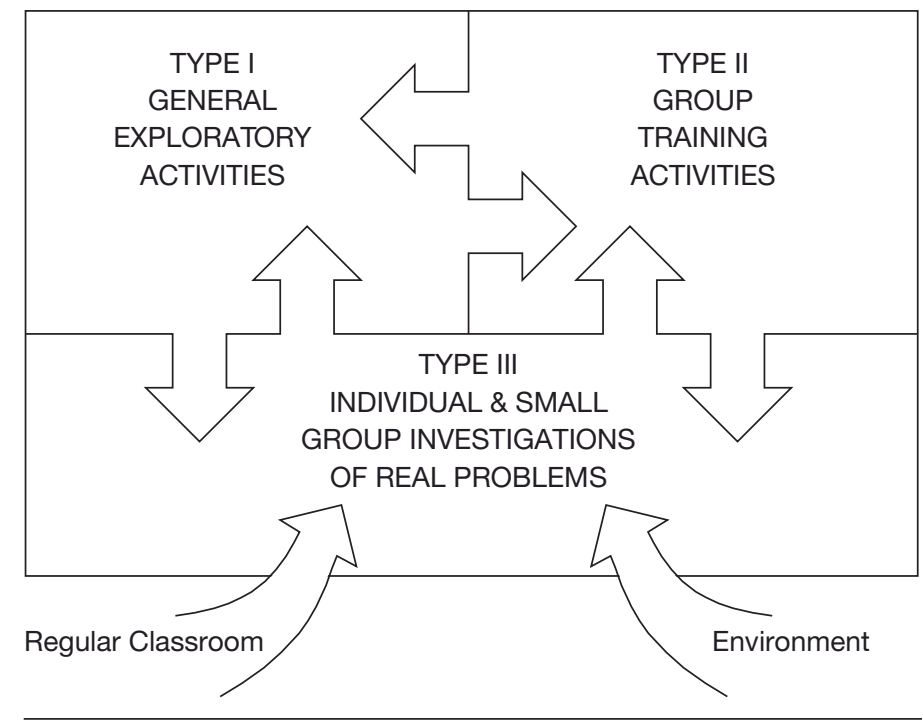

Fonte: https://gifted.uconn.edu/wp-content/uploads/sites/961/2015/01/cubetrid.pdf
2) Tradução dos itens figura: Tipo I: atividades gerais e exploratórias; Tipo II: grupo com atividades de formação/ capacitação; Tipo III: pesquisas indivi- duais ou em pequenos grupos sobre problemas reais; Sala de aula regular; Ambiente. 
A Figura 1 auxilia o entendimento da não linearidade da proposta do Modelo Triádico de Enriquecimento. O estudante pode avançar e retroceder nas atividades relacionadas com cada tipo de enriquecimento de acordo com a sua necessidade de aprendizagem, pesquisa e envolvimento. Este modelo valoriza a singularidade do desenvolvimento do estudante.

Além disso, é válido destacar que, exercendo o enriquecimento desta maneira flexível e sugestiva, é mais fácil de se conseguir contemplar as diversidades e peculiaridades que advêm da combinação entre AH/SD e as diferentes áreas do conhecimento e a individualidade de cada pessoa.

A propósito de tais possibilidades, convém apresentar as explicações de Sabatella e Cupertino (2007) quanto ao enriquecimento. Segundo as autoras, quando o enriquecimento acontece de forma extracurricular, ele pode ser sistematizado por meio de programas de desenvolvimento pessoal e programa com mentores, sendo que são:

"implementados em pequenos grupos, buscam promover o desenvolvimento das habilidades de relacionamento interpessoal, de reflexão e a atração pelo conhecimento. Os últimos tratam de formas muito individualizadas de ensino, por meio de mentores que auxiliam no desenvolvimento de talentos específicos". (Sabatella, Cupertino, 2007:76)

O projeto de extensão PIT oferece atividades organizadas nos três tipos de enriquecimento, bem como combinam as modalidades de organização citadas acima, uma vez que, o trabalho com mentores pode acontecer através de um grupo de interesse. Logo, as questões de interação e relacionamento estão sendo desenvolvidas concomitantemente às de estímulo ao potencial, uma vez que, ao mesmo tempo em que têm acesso às atividades de enriquecimento na sua(s) área(s) de interesse, os estudantes convivem e interagem com outros estudantes e com um mentor. Cabe ainda ressaltar que o Modelo Triádico de Enriquecimento (Renzulli, Reis, 2012; Renzulli, 2004) pode ser utilizado em duas formas de organização, para desenvolvimento pessoal e programa com mentores, sendo elas efetivadas em separado ou concomitantemente.

O artigo teve sua metodologia embasada na investigação qualitativa, sendo que para Oliveira (2008) e Gil (2010), a pesquisa qualitativa é um estudo aprofundado, detalhado e explicativo do objeto escolhido para investigação, através da busca de informações legítimas. Desta forma, a pesquisa embasou-se e foi constituída a partir dos documentos que caracterizam o projeto de extensão PIT e das falas de 24 estudantes que frequentam este projeto, com idade entre 10 e 15 anos, de ambos sexos, que participaram do estudo por meio da realização de uma entrevista semiestruturada (Gil, 2010). Este artigo advém de parte dos estudos realizados em uma dissertação de mestrado, defendida em 2013, sendo que a pesquisadora fez parte deste projeto desde o ano de 2006. Os responsáveis pelos estudantes assinaram o Termo de Consentimento Livre e Esclarecido (TCLE) para participar da coleta de dados que resultou neste artigo. O projeto foi aprovado pelo Comitê de Ética em Pesquisa da Universidade Federal de Santa Maria (UFSM).

Utilizou-se da análise de conteúdo (Bardin, 2011) para investigar os documentos estudados e as falas dos estudantes, sendo que "A análise de conteúdo é um conjunto de técnicas de análise de comunicações" (Bardin, 2011:37). As entrevistas foram abordadas por meio de análise transversal sintética, que se subdivide em dois níveis: A decifração estrutural e a transversalidade temática. A decifração estrutural implica em buscar os dados para a pesquisa a partir da compreensão do interior da fala da pessoa entrevistada. Isso exige do pesquisador que, a cada nova apreciação, desfaça as impressões das análises anteriores para ter uma visão quase totalmente neutra sobre o conteúdo da entrevista analisada no momento (Bardin, 2011).

Em um segundo momento, fez-se a análise do conteúdo abordado de forma a encontrar os temas subjacentes à fala do entrevistado que, em alguns momentos, aparecem de forma explicita e, em outros, não. Este segundo momento da apreciação, Bardin (2011) chama de transversalidade temática. Após a análise transversal sintética, elegeu-se as categorias de análise a partir dos elementos de significação presentes nas respostas dos estudantes aos questionamentos da entrevista semiestruturada.

No campo dos resultados estudados neste artigo, apresenta-se a caracterização do projeto de extensão PIT, com base na análise de conteúdo do projeto e dos relatórios das suas ações. Este projeto é vinculado à Universidade Federal de Santa Maria (UFSM) que oferece enriquecimento extraescolar intra e extracurricular, com predomínio de ações no âmbito da última configuração de enriquecimento. O projeto existe desde o ano de 2001, é coordenado pela professora Soraia Napoleão Freitas, e funciona na cidade de Santa Maria, Brasil, com um número aproximado de 60 alunos 
envolvidos, 40 profissionais e oito escolas. Tinha como principais objetivos: Receber e encaminhar ao programa alunos identificados como tendo características de Altas Habilidades/Superdotação que frequentam as séries iniciais do Ensino Fundamental da rede Estadual e Municipal de Santa Maria; oportunizar a estes alunos atividades e experiências significativas com orientações sistemáticas incentivando a área de interesse de cada um, assim como do grupo; realizar parceria com acadêmicos, especialistas, grupos de pesquisa e extensão da UFSM a fim de que estes propiciem aos alunos participantes do PIT experiências de investigação e pesquisa referentes às diversas áreas do conhecimento que apresentarem interesse; organizar grupo de estudos com os pais dos alunos que participam do PIT e demais membros da comunidade que tiverem interesse, a fim de que sejam realizadas palestras e discussões sobre a temática em questão. Os profissionais envolvidos são professores de Pedagogia de Educação Especial, de Educação Física, todos vinculados à pós-graduação ou pós-graduados em Educação e profissionais diversos convidados a desenvolver determinadas atividades. Todos os profissionais vinculados ao PIT tinham formação específica em AH/SD, seja por meio de cursos de breve duração e/ou de pósgraduação. Estes profissionais são em sua maioria voluntários. Todo ano o projeto concorre a bolsas institucionais de iniciação científica para estudantes de graduação que são acompanhadas de um valor monetário para despesas gerais do projeto.

Os principais autores que compõem o referencial teórico do projeto são: Joseph S. Renzulli; Howard Gardner; Zenita Cunha Guenther; Saturnino de La Torre. Uma escola estadual cede seu espaço para realização das atividades do PIT que acontecem aos sábados no turno matutino.

A maioria dos estudantes que participam do PIT são indicados através das ações do Projeto de Pesquisa "Da identificação à orientação de alunos com características de altas habilidades/ superdotação". Inicialmente são realizados convites às escolas para participar do processo de identificação dos alunos com $\mathrm{AH} / \mathrm{SD}$, depois realizam-se encontros informativos com os professores da instituição sobre a temática das altas habilidades/ superdotação. O processo segue com a aplicação e instrumentos/ questionários elaborados por Freitas e Pérez (2010) para a indicação de características de AH/SD: Autonomeação e Nomeação por colegas, um questionário para professores e outro para pais e/ ou responsáveis que será que será respondido pelos pais e/ ou responsáveis dos estudantes anteriormente indicados pelos colegas, pela autonomeação e pelos professores. Com a análise de todos os instrumentos, serão alcançados dados que demonstram a quantidade de estudantes com características de AH/SD indicados em cada turma e quais são as características destes.

Conta-se com o apoio de professores, profissionais, acadêmicos, ou até mesmo outros projetos da Universidade Federal de Santa Maria, para auxiliar no aprofundamento da área de conhecimento trabalhada no programa de enriquecimento extra escolar. São exemplos de cursos de graduação que já tiveram ações desenvolvidas no PIT: Física, Matemática, Enfermagem, Zootecnia, Música, Engenharia Elétrica, Educação Física, História. Grupos do Programa de Educação Tutorial da Universidade Federal de Santa Maria, além de profissionais voluntários convidados para participações especiais/eventuais pela equipe executora do projeto.

As atividades acontecem em Grupos de interesse nos quais são realizadas atividades do Tipo I, II e III (Renzulli, 2004, 2012), que são implementadas em forma de projetos de interesse. Também são realizadas atividades especiais que são eventos nos quais a equipe do projeto tem a oportunidade de reunir todos os grupos de interesse, com a finalidade de promover laços afetivos e a troca de conhecimentos/habilidades com os colegas de outros grupos. Exemplos de atividades especiais já desenvolvidas são: Visita ao Jardim Botânico da Universidade Federal de Santa Maria e Aprendizagem de Técnicas Circenses.

Ainda, possui um Grupo de pais e comunidade interessada que consiste-se em um grupo de discussões sobre a temática $\mathrm{AH} /$ $\mathrm{SD}$ que acontece simultaneamente às atividades dos grupos de interesse. Desde o ano de 2012, por meio do projeto de pesquisa "Acessibilidade na educação" que tem suas ações vinculadas ao PIT, iniciou-se um trabalho de assessoria educacional e acompanhamento pedagógico junto às escolas dos alunos participantes do PIT. Anteriormente á isso o acompanhamento era mais focado em avisos e informações envolvendo o PIT, bem como no retorno à escola quanto à participação dos seus estudantes no PIT e em ocasiões em que a própria escola solicitava ao projeto uma conversa e/ou intervenção junto à determinado estudante. Apresenta-se, a seguir, no Quadro 1, as falas dos estudantes sobre o Programa de Enriquecimento Extraescolar. Tratase a categoria de análise que surgiu das entrevistas foi "os programas na visão dos estudantes com AH/SD": 
Quadro 1. A visão geral dos estudantes com AH/SD do projeto de extensão PIT

\begin{tabular}{ll}
\hline Estudantes & Falas \\
\hline A & "To participando das aulas de inglês, só. São legais, a gente \\
conversa bastante que é bem legal (...) e não tem tanta escrita."
\end{tabular}

C "Lá a gente faz atividades sobre o nosso interesse, eu aprendi coisas que eu não sabia ainda, agora em ciências eu to aprendendo sobre as cores (...) ano passado eu tava no grupo da tecnologia, agora com o de ciências nós fomos duas vezes lá na universidad."

D "Logo no começo foi um pouquinho rápido demais porque eu entrei acho dois meses antes da Feira de Ciências, a gente quando chega assim uns dois, seis meses antes, a gente se foca muito nela e faz um trabalho bem legal (...) na sexta série como eu comecei desde o começo mesmo, deu pra aprender coisas legais já, e mais no que eu queria mesmo. (...) Os professores buscam muito pela prática, através de protótipos mesmo que eles fazem, também usam muito o computador, eles também escrevem, mas como é pra ser uma coisa diferenciada da escola eles não tem que ficar escrevendo tanto assim, a gente tem que aprender, aprendendo tá bom."

E "eu sentei aqui e ela pegou um papel e foi fazendo perguntas em inglês, metade das perguntas eu não entendi nada, inglês do colégio fraquinho e o inglês bonzão daqui, aí ela foi fazendo as perguntas e eu fui respondendo."

$\mathrm{F}$

“Desenhos né, primeiro eu entrei na área de artes, depois surgiram novas oportunidades não na área de artes, mas em outras áreas, como por exemplo, inglês, então eu fui, as aulas eram lá no (nome do centro) mesmo, aí, só que aí vieram outras oportunidades, daí apareceu a oportunidade de ir pra (nome de universidade), e quanto ao curso de artes lá acabou (...) aí surgiram novas propostas, e eu comecei estudar com a professora R. (...) depois veio o (grupo de artes), que é o que eu to fazendo também às sextas-feiras, e tem o de hoje, aí teve essa outra oportunidade de fazer esse outro curso de artes."

\begin{tabular}{|c|c|}
\hline Estudantes & Falas \\
\hline G & $\begin{array}{l}\text { "Cheguei lá e todo mundo me deu oi né, aí depois eu fiz um monte } \\
\text { de amigo lá e aí ficou assim, achei bem legal. (...) Tem umas } \\
\text { oficinas de coisa, tem de ciências, de história (...) só que quando } \\
\text { começou estas oficinas eu ficava mudando sempre, comecei } \\
\text { com musica, depois fui pra 'espaço', depois fui pra jogos.” }\end{array}$ \\
\hline $\mathrm{H}$ & $\begin{array}{l}\text { "Bom, foi muito bom, eu trabalhava, eu desenhava, fazia meus } \\
\text { trabalhos lá no (nome do programa), com a M., lá eu fazia só } \\
\text { desenhos, porque lá não tinha assim muitos materiais, aí depois } \\
\text { esse ano eu vim pra cá (...) e comecei a desenhar, a pintar várias } \\
\text { coisas. A elas me mostram livros, P. ela me ensina a pintar assim } \\
\text { melhor, entendeu?" }\end{array}$ \\
\hline I & $\begin{array}{l}\text { "quando eu vinha adorava vim, pena que durou pouco tempo, } \\
\text { todo dia tinha uma coisinha diferente, um dia era, tinha varias } \\
\text { coisinhas legais, umas vezes era lá em cima, outras vezes era na } \\
\text { caverna, com lições de escrever, brincar, montar quebra-cabeça, } \\
\text { é bem divertido." }\end{array}$ \\
\hline J & $\begin{array}{l}\text { "A é muito legal, é muito legal ficar lá no (nome do programa), } \\
\text { no (nome do programa) eu acho o lugar mais bom pra ir, lá você } \\
\text { se expressa também com os seus colegas e também com as } \\
\text { professoras, eles te dão uma ideia do que tu pode fazer ou se } \\
\text { não eu do uma ideia pra eles do que eles podem fazer. A são as } \\
\text { oficinas, eu adoro as oficinas." }\end{array}$ \\
\hline $\mathrm{K}$ & $\begin{array}{l}\text { "Bom, a gente sempre tá conversando sobre tudo, eu sempre } \\
\text { to contando pra ela como está as coisa na escola, e em casa } \\
\text { também, mas geralmente a gente sempre acaba fazendo a } \\
\text { mesma coisa, eu sempre to desenhando, pintando, fazendo } \\
\text { alguma coisa." }\end{array}$ \\
\hline L & $\begin{array}{l}\text { "Eu gosto bastante porque tem a minha vó aqui, isso é mais } \\
\text { importante (...) deixa eu fazer aula de pintura, deixa eu fazer aula } \\
\text { de desenho, eu sempre quis aperfeiçoar na arte, o melhor da vida } \\
\text { é você ir se aperfeiçoando, fazer o melhor que você pode." }\end{array}$ \\
\hline M & $\begin{array}{l}\text { "joguinho de memória pra treinar assim, montar uma maquete de } \\
\text { um quarto, e eu ainda continuo, nas maquetes eu fiz, eu sou ruim } \\
\text { mesmo, só maquete mesmo, eu continuei fazendo os bonecos." }\end{array}$ \\
\hline $\mathrm{N}$ & $\begin{array}{l}\text { "Eu gostei de todos, gostei, a robótica faz na (nome de } \\
\text { universidade), ainda tá muito bom, mitologia eu fazia aqui, depois } \\
\text { a gente começou a frequentar o Centro G., e eu fui começando } \\
\text { a gostar mais ainda, lá a gente ganha os livros, aí vai falando da } \\
\text { gramatica ou as frases mais fáceis e vai ensinando você a falar." }\end{array}$ \\
\hline
\end{tabular}

Fonte: elaborado pela autora. 


\begin{tabular}{|c|c|c|c|}
\hline Estudantes & Falas & Estudantes & Falas \\
\hline $\mathrm{O}$ & $\begin{array}{l}\text { "Em relação ao (nome do programa), com a psicóloga que eu } \\
\text { fazia o acompanhamento era bem bom, porque eu acho que o } \\
\text { entendimento do superdotado de uma outra pessoa é diferente, } \\
\text { então é bom você ter uma pessoa que te entenda, e no inglês, } \\
\text { que eu faço inglês acompanhado no (nome do programa) é } \\
\text { melhor porque as outras escolas de inglês que eu participei às } \\
\text { vezes (...) e aqui (...) eu consigo me expressar melhor e entender } \\
\text { melhor, não o que tem diferente, digamos que você não a } \\
\text { diferente, mas tem uma pessoa igual a você." }\end{array}$ & $\mathrm{T}$ & $\begin{array}{l}\text { "A gente faz muitas brincadeiras, passeios, passeio só de vez } \\
\text { em quando, é legal, o mais legal foi quando a gente foi pro (...) né, } \\
\text { por causa dos carros, } \\
\text { eu queria que as pessoas de todos os grupos pudessem ir. } \\
\text { (...) Eu participo, eu quase nunca falto, só quando eu to doente, } \\
\text { quando eu to doente ou quando eu tenho que cuidar da minha } \\
\text { irmã. O meu grupo é o de esportes, a gente faz bastante } \\
\text { brincadeira, jogo, eu fiz meu aniversário no (nome do programa). } \\
\text { (...) Minha mãe não gosta muito que eu venha porque é difícil de } \\
\text { eu vim, morando longe, eu faço esforço pra vim." }\end{array}$ \\
\hline $\mathrm{P}$ & $\begin{array}{l}\text { "Este programa é muito bom porque a gente participa de } \\
\text { eventos, eu participava da Feira de Ciências e Tecnologia, daí } \\
\text { nos dois anos que eu fiz a gente apresentou projetos diferentes } \\
\text { (...) Eu gosto de mostrar a minha ideia, se eu tenho uma ideia boa } \\
\text { mostro pra pessoas pra ver se elas concordam, se vale a pena } \\
\text { ir atrás, eu gosto de fazer isso (...) a gente tá falando mais ou } \\
\text { menos inglês, porque a gente não tá no avançado, tá início ainda. } \\
\text { (...) Depois eu quero estudar Mandarim, eu me apaixono por esta } \\
\text { língua, principalmente por causa dos países onde se localiza." }\end{array}$ & $U$ & $\begin{array}{l}\text { "A participação minha é, frequento direto, não gosto de faltar } \\
\text { não, é uma vez só, na sexta-feira lá na (nome de universidade), } \\
\text { eu gosto muito de vim no (nome do programa), fazer aula de } \\
\text { robótica, nossa eu amo muito, não tem muito o que falar não, } \\
\text { mas eu venho direto, nunca falto. } \\
\text { Eu participei de artes, logo, primeiro lugar lá do (nome do } \\
\text { centro), na verdade eu praticamente inventei um grupo, porque } \\
\text { eu gostava de ir no (nome do centro)." }\end{array}$ \\
\hline Q & $\begin{array}{l}\text { "Tipo é muito legal, aprender principalmente, eu aprendi } \\
\text { mais, chegava lá, aí tocava, ensaiava e tal, era muito legal (...) } \\
\text { e chamava a gente pra sala de musicalização, daí a gente } \\
\text { ensaiava, tocava, aprendia as notas, ensaiava demais." }\end{array}$ & V & $\begin{array}{l}\text { "Eu já fiz inglês aqui, muito bom, também não é muita coisa que } \\
\text { eu fiz, porque eles ajudam as pessoas, assim, especificada nas } \\
\text { áreas aqui de dentro, robótica, xadrez, e eu não me despertei } \\
\text { em nada aqui de dentro [...] No vale social, eu fui pro Judô[...]" }\end{array}$ \\
\hline$R$ & $\begin{array}{l}\text { "É muito legal, foi muito legal estar com mais pessoas parecida } \\
\text { com a gente, aí você consegue conversar é diferente do colégio, } \\
\text { é meio uma cabeça doida que a gente fala." }\end{array}$ & W & $\begin{array}{l}\text { "É bem legal, todos os sábados tem uma coisa nova, e eu } \\
\text { procuro sempre participar de todas. (...) É uma forma mais fácil } \\
\text { de aprender, ou que envolve as coisas que a gente não trabalha }\end{array}$ \\
\hline \multirow[t]{3}{*}{$S$} & $\begin{array}{l}\text { "Eu acho que a parte que eu mais participei foi esse ano essa } \\
\text { parte de tecnologia, que eu achei bem interessante (...) foi nessa } \\
\text { parte que a gente tinha que montar, primeiro a gente tinha que } \\
\text { montar com materiais recicláveis, depois a gente começou a }\end{array}$ & & $\begin{array}{l}\text { técnicas pra aprender não é só a sala de aula o tempo inteiro. } \\
\text { Porque a gente sai ao ar livre pra aprender as coisas, não fica só } \\
\text { dentro da sala de aula, a gente aprende de uma forma diferente, } \\
\text { aprende brincando ou fazendo atividades." }\end{array}$ \\
\hline & $\begin{array}{l}\text { começou a usar e fazer umas coisa bem legal. (...) é só ajudar, } \\
\text { elas diziam que tinha que inventar alguma coisa e foi isso que eu } \\
\text { pensei em fazer né." }\end{array}$ & $x$ & $\begin{array}{l}\text { "Eu acho que o (nome do programa) é bem legal por causa que } \\
\text { ensina coisas novas que a gente poderia não aprender assim } \\
\text { no colégio e atividades assim. (...) Agora eu to no grupo de }\end{array}$ \\
\hline & & & $\begin{array}{l}\text { que a gente não conhecia, tipo um, o basquete que é pras pessoas } \\
\text { que não tem pernas, não tem o movimento das pernas, daí elas } \\
\text { jogam sentadas." }\end{array}$ \\
\hline
\end{tabular}


O Programa de Incentivo ao Talento -PIT— há muitos anos e desenvolve suas atividades com excelência e empenho na qualificação dessas, contando com profissionais com formação inicial em Educação Especial. Apesar do PIT contar essencialmente com profissionais voluntários, espaço cedido e precisar concorrer anualmente há editais para ter algum tipo de recurso financeiro, não deixa de proporcionar aos estudantes vivências em outros espaços educacionais, materiais e ou recursos, para que possam ser contempladas as suas demandas.

Logo, nota-se que apesar das dificuldades no desenvolvimento desta ação de extensão, o projeto consegue desenvolver suas ações atendendo o estudantes com $\mathrm{AH} / \mathrm{SD}$, que por vezes não recebem $o$ atendimento adequado nas escolas que frequentam. Isso acontece, dentre outros, pela dificuldade de identificação destes estudantes que acabam por estar marginalizados no seu direito à um atendimento especializado.

Pelas falas dos estudantes entende-se que as atividades estão organizadas em áreas e subáreas de interesse, podendo ser desenvolvidas em grupo ou individualmente, estando em consonância com a discussão teórica registrada anteriormente (Kunkel, 2010; Renzulli, 2004, 2012; Renzulli, Reis, 2012; Sabatella, Cupertino, 2007). A inexistência de registros exclusivamente escritos é bastante destacada pelos estudantes, o que remete à questão da expressão nas diferentes inteligências múltiplas que, muitas vezes, não necessita passar pela escrita para que sejam verificadas suas aprendizagens.

As atividades desenvolvidas, por vezes, estão além do que é previsto no currículo do ano em que o estudante se encontra. Como destacam os estudantes B e C, são conhecimentos mais avançados que partem das demandas trazidas por eles, e que, possivelmente demorariam muito mais para conhecerem e experienciarem, se não estivessem participando do projeto. A maioria dos estudantes destaca a oportunidade de vivenciar conhecimentos científicos e aprofundados nas atividades desenvolvidas, aproximando-os da(s) sua(s) área(s) de interesse e ampliando as possibilidades de aplicação das suas aprendizagens em projetos próprios, individuais e/ou coletivos. A possibilidade de conhecer e visitar com maior frequência espaços privilegiados em determinadas áreas, com materiais, recursos humanos e possibilidades de vivências extremamente especializadas, como laboratórios na universidade, foi ressaltada pelos estudantes como ação importante do programa de enriquecimento extraescolar. Muitos deles, ao longo da sua trajetória escolar, talvez nunca tivessem esta oportunidade. É importante destacar que existem as instituições parceiras dos programas, que oferecem atividades para os estudantes com AH/SD.

Guenther (2007) afirma que estes encaminhamentos e parcerias auxiliam muito na constituição da acessibilidade educacional desses estudantes, uma vez que apresentam demandas diferenciadas de contato com o conhecimento. Por meio das ações do projeto, os estudantes com AH/SD têm oportunidade de mostrar seus projetos e atividades à sociedade em feiras e exposições, internas ou externas, podendo ver seu trabalho apreciado por outras pessoas. Isso propicia que se sintam valorizados nas suas capacidades e estimulados a buscar desenvolver e crescer na(s) sua(s) AH/SD. Para além de desenvolver atividades e profundar seus conhecimentos na(s) sua(s) área(s) de interesse, os estudantes podem participar de outros grupos e/ou atividades e, assim, podem ampliar seus conhecimentos e buscar aperfeiçoar aqueles relativos à(s) área(s) que têm mais dificuldade.

Constata-se o importante papel dos interlocutores privilegiados, como pessoas que tem conhecimento específico na área que qualifica seu trabalho junto a estes estudantes, especialmente, na fala dos estudantes $\mathrm{G}, \mathrm{O}$ e R. Estes referenciam os laços afetivos que têm no programa extraescolar do qual participam, bem como o estudante $\mathrm{J}$ destaca que se sente estimulado pela mediação pedagógica no Programa de Enriquecimento Extraescolar. Por fim, sobre a análise do Quadro 1, é válido destacar o que é apontado pela aluna T: dificuldade em ir até o local, onde o programa do qual participa é desenvolvido. Esta barreira, determinada pelo valor do transporte urbano, é enfrentada por outros estudantes também, dentre esses, os estudantes $\mathrm{H}$ e $V$, além de outros que participam dos programas e não foram sujeitos desta pesquisa.

\section{Considerações finais}

Mesmo que existam salas de recursos que atendam toda a demanda da escola frente ao atendimento aos estudantes com $\mathrm{AH} / \mathrm{SD}$, ainda assim não se pode descartar a necessidade da existência de espaços extraescolares que são muito diferenciados em suas estruturas e funcionamentos, dentre outros, por meio de projetos de extensão universitária. Acredita-se, pois, que as atividades desenvolvidas nestes contribuem para a educação de crianças e adolescentes com AH/SD, qualificando o aproveitamento do seu potencial, enquanto atende as suas necessidades educacionais especiais. 


\section{Referências bibliográficas}

Alencar, E. M. L. S.; Fleith, D. S. (2001). Superdotados: determinantes, educação e ajustamento. $2^{\text {a }}$. ed. São Paulo: EPU.

Bittelbrunn, I. B. A. (2003). O silêncio da Escola Pública: Um estudo sobre os programas de atendimento aos alunos com indicadores de superdotação no Estado de Mato Grosso do Sul. Ivonete Antunes Bittencourt Bittelbrunn. Campo Grande, MS. Dissertação (mestrado). Fundação Universidade Federal de Mato Grosso do Sul - Educação.

Brasil (2008). Política Nacional de Educação Especial na Perspectiva da Educação Inclusiva. Brasília, DF. Disponível em: http://portal.mec.gov.br/seesp/arquivos/pdf/ politica.pdf (acesso em 11 nov. 2010).

Carvalho, S. M. S. (2009). Reflexões sobre a extensão na universidade pública brasileira. ParticipAção, (16), 12-20. Brasília.

Cruz, C. (2007). A Construção de práticas de atendimento ao aluno com altas habilidades/superdotação no Espírito Santo: alinhavando escritos e escutas. Carly Cruz. Vitória, ES. Dissertação (mestrado). Universidade Federal do Espírito Santo, Programa de Pós-Graduação em Educação.

Fortes, C. C. (2008). Contribuições do PIT - programa de incentivo ao talento no processo de aprendizagem e desenvolvimento de um aluno com altas habilidades. Caroline Côrrea Fortes. Santa Maria, RS. Dissertação (mestrado). Universidade Federal de Santa Maria, Programa de Pós-Graduação em Educação.

Freitas, S. N.; Pérez, S. G. P. B. (2012). Altas Habilidades/Superdotação: atendimento educacional especializado. $2^{\text {a }}$ ed., revista e ampliada. Marília: ABPEE. Gerson, K.; Carracedo, S. (2007). Niños com altas capacidades a la luz de las múltiples inteligências. $1^{\text {a }}$ ed. Buenos Aires: Magistério del Río de la Plata. Gil, A. C. (2010). Como elaborar projetos de pesquisa. 5a . ed. São Paulo: Atlas. Guenther, Z. C. (2007) Capacidade e Talento - Um programa para a Escola. São Paulo: EPU.

INEP (2009). Sinopse estatística da educação básica 2009. Brasília: INEP. Disponível em: http://www.inep.gov.br/basica/censo/default.asp (acesso em 10 ab. 2011). Kunkel, C. (2010). A Primeira Escola Baseada nas Inteligências Múltiplas no Mundo: A história da Key Learning Community. In Gardner, H. et al., Inteligências
Múltiplas ao redor do mundo (cap. 24, pp. 304-317). Porto Alegre: Artmed.

Magalhães, M. G. M. S. de (2006). Programa de Atendimento ao Superdotado da Secretaria de Estado de Educação do Distrito Federal (1991-2002): inclusão social ou tergiversação burocrática? Marília Gonzaga Martins Souto de Magalhães. Brasília, DF. Tese (doutorado) Universidade Federal de Brasília, Instituto de Sociologia.

Moreira, L. C. et al. (2011). Ingresso e permanência na Universidade: alunos com deficiências em foco. Educar em Revista, (41, jul./set.), 125-143. Curitiba.

Nakano, T. de C.; Siqueira, L. G. G. (2012). Revisão de publicações periódicas brasileiras sobre superdotação. Revista Educação Especial, 25(43, maio/ago), 249-266. Santa Maria.

Nicoloso, C. M. F.; Freitas, S. N. (2002). Questões norteadoras a uma proposta de atendimento a portadores de altas habilidades: conceituação, currículo e sugestão de uma atividade de enriquecimento. Cadernos de Ensino, Pesquisa e Extensão, (51), 1-26. Santa Maria.

Oliveira, M. M. de (2008). Como fazer pesquisa qualitativa. 2. ed. Petrópolis, RJ: Vozes.

Pinto, R. R. M. (2002). Avaliação das Práticas Educacionais Implementadas em um Programa de Atendimento a Alunos Superdotados e Talentosos. Renata Rodrigues Maia-Pinto. Brasília, DF. Dissertação (mestrado). Universidade de Brasília, Mestrado em Psicologia.

Renzulli, J. S. (2004). O que é esta coisa chamada superdotação, e como a desenvolvemos? Uma retrospectiva de vinte e cinco anos. Tradução: Susana Graciela Pérez Barrera Pérez. Educação, XXVII(1, jan./abr.), 76-131. Porto Alegre: RS.

Renzulli, J. S.; Reis, S. M. (s/f). The Schoolwide Enrichment Model Executive Summary. Disponível em: http://www.gifted.uconn.edu/sem/semexec.html (acesso em 16 mar. 2012).

Sabatella, M. L.; Cupertino, C. M. B. (2007). Práticas Educacionais de Atendimento ao Aluno com Altas Habilidades/Superdotação. In A Construção de Práticas Educacionais para Alunos com Altas Habilidades/Superdotação (pp. 67-80). Brasília: Ministério da Educação. 